\title{
Effect of Ultrafine Ground Granulated Blast-Furnace Slag (UFGGBFS) and Copper Slag on Ambient Cured Geopolymer Concrete
}

\author{
Vijayasarathy Rathanasalam*, Jayabalan Perumalsami, Karthikeyan Jayakumar \\ Department of Civil Engineering, National Institute of Technology, Trichy 620015, TamilNadu, India
}

Corresponding Author Email: vijayasarathy.civil@gmail.com

https://doi.org/10.18280/acsm.430603

Received: 15 August 2019

Accepted: 6 November 2019

\section{Keywords:}

copper slag, fly ash, geopolymer concrete, rapid chloride penetration test, ultrafine ground granulated blast furnace slag

\begin{abstract}
This paper explores deep into the effects of mineral admixtures, e.g. ultrafine ground granulated blast-furnace slag (UFGGBFS) and copper slag (CPS), on ambient cured geopolymer concrete (GPC). First, a GPC was prepared from mineral admixtures like the UFGGBFS, fly ash and the CPS, and alkali activators like sodium hydroxide $(\mathrm{NaOH})$ and sodium silicate $\left(\mathrm{Na}_{2} \mathrm{SiO}_{3}\right)$. Then, $10 \mathrm{M}, 12 \mathrm{M}$ and $14 \mathrm{M}$ GPC samples were created, with UFGGBFS content of $0 \%, 5 \%, 10 \%$ and $15 \%$, respectively. These samples were subjected to compressive strength tests, rapid chloride permeability test (RCPT), X-ray diffractometry (XRD) and scanning electron microscopy (SEM). The results show that the GPC samples achieved good compressive strength after 56 days of ambient curing; with the increase of the UFGGBFS content, the porosities and RCPT values of the samples decreased after 180 days of ambient curing; the samples with different mix ratios all showed good performance with the growth in molar concentration. The research results shed new light on the development of eco-friendly alternatives to cementitious GPC.
\end{abstract}

\section{INTRODUCTION}

An increase in population growth increases infrastructure which leads to an increased quantity of construction material. One of the important binding materials in concrete is cement, usage of cement is increasing abundantly. Harmful gases which are released during the production of cement are the main reason for the greenhouse effect [1]. $\mathrm{CO}_{2}$ emission may reach $50 \%$ in the year 2020 [2]. To overcome these issues researchers have worked on alternate binding material, one such material which has come to light is Geopolymer Concrete (GPC). The usage of alkali-activated concrete reduces the $\mathrm{CO}_{2}$ emission along with good mechanical strength and stability during harsh environment [3, 4]. Mechanical properties of Alkali activated cementitious materials were compared to be good than Portland cement and performance was found to be good in the chemical and acid attack [5]. Wastes from industry such as fly ash, rice husk are effectively utilized [6]. Several works highlight that heat curing improves the strength characteristics of GPC [7-9]. Applying heat curing in field applications is one of the biggest limitations [10]. Incorporation of Alccofine improved the mechanical properties of GPC at ambient temperature, further strength increases with an increase in $\mathrm{NaOH}$ molarity. [11]. From previous studies, it is known that the addition of calcium products improved the strength and microstructure of GPC making it durable [12-14]. The worldwide quantity of CPS was found to be approximately 24.6 million tonnes per annum [15]. Using of CPS as fine aggregate in GPC improved the strength value when compared to control concrete. Addition of CPS reduces water absorption and porosity of GPC [16]. CPS has wide applications in the manufacturing of glass ceramics, tiles and used as an aggregate in the construction industry and also as mineral admixture [17-20]. Literature studies have shown that heat curing improves the strength performance of GPC than ambient curing. Porosity, RCPT performance, XRD and SEM morphology are found to be better in GPC. Due to less availability of literature regarding UFGGBFS and CPS based GPC; this work is focused on the grey area of GPC research mainly 56-day compressive strength of GPC subjected to ambient curing, early performance of GPC at 1 day and 7 days were studied by numerous researchers. Experimental results of RCPT and porosity were compared. Large investigations were made on strength and durability characteristics and part of the investigation is made in this paper.

\section{EXPERIMENTAL INVESTIGATION}

\subsection{Materials}

Dry fly ash of Class-F obtained from Mettur, India was used in this study and shown their properties in Figure 1. CPS collected from Thoothukudi, India was used as fine aggregate according to IS: $383-1970$ [21]. Figure 2 details the properties of CPS. The uncrushed coarse aggregate of size $12.5 \mathrm{~mm}$ with specific gravity 2.83 pertaining to IS: $383-1970$ [21] was used. UFGGBFS (Alccofine) a low calcium silicate micro-fine material conforming to [22] was replaced partially with fly ash. Table 1 highlights the properties of UFGGBFS. Locally available alkali activators such as $\mathrm{NaOH}$ and $\mathrm{Na}_{2} \mathrm{SiO}_{3}$ were procured in order to enhance the geo-polymerization process. Naphthalene sulphonate made Superplasticizer as per IS 9103: 1999 [23] was used to enhance workability. 


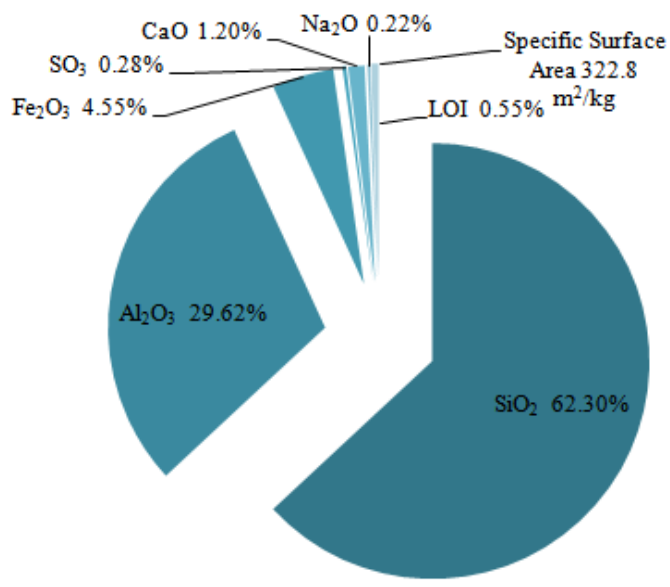

Figure 1. Properties of fly ash

\subsection{Mix proportion and making of GPC}

Based on previous work GPC mix proportions were made after doing several trial mixes with and without UFGGBFS [24-26]. UFGGBFS was restricted to $15 \%$. 10M, 12M and $14 \mathrm{M} \mathrm{NaOH}$ solutions were prepared 24 hours before mixing,

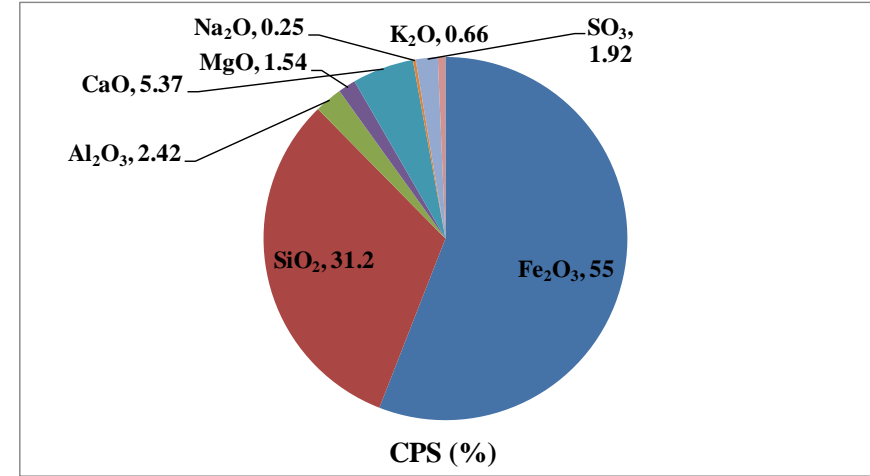

Figure 2. Properties of CPS

sodium silicate was taken 2.5 times the $\mathrm{NaOH}$ solution. UFGGBFS was partially replaced with fly ash. All the different mixes were prepared by mixing the alkaline solution with UFGGBFS, fly ash, CPS and coarse aggregate, $2 \%$ of superplasticizer were added for workability purpose. Table 2 shows the mix proportion of GPC.

Table 1. Properties of UFGGBFS

\begin{tabular}{cccc}
\hline \multicolumn{2}{c}{ Physical properties } & \multicolumn{2}{c}{ Chemical composition } \\
\hline Property & Values & Property & Values \\
\hline Specific Surface Area & $12000 \mathrm{~cm}^{2} / \mathrm{gm}$ & Silica $\left(\mathrm{SiO}_{2}\right)$ & $35 \%$ \\
Specific Gravity & 2.72 & $\mathrm{CaO}$ & $34 \%$ \\
Bulk Density $\left(\mathrm{kg} / \mathrm{m}^{3}\right)$ & $600-700$ & Alumina $\left(\mathrm{Al}_{2} \mathrm{O}_{3}\right)$ & $24 \%$ \\
Average particle size & 4 to 6 microns & Magnesia $(\mathrm{MgO})$ & $8 \%$ \\
\hline
\end{tabular}

Table 2. Mix proportion for GPC

\begin{tabular}{cccccc}
\hline $\begin{array}{c}\text { Mix } \\
(\mathbf{U F G G B F S})\end{array}$ & $\begin{array}{c}\text { Fly Ash } \\
\left(\mathbf{k g} / \mathbf{m}^{\mathbf{3}}\right)\end{array}$ & $\mathbf{N a O H}($ for 10M,12M and 14M) \\
$\left(\mathbf{k g} / \mathbf{m}^{\mathbf{3}}\right)$ & $\begin{array}{c}\mathbf{N a 2}^{\mathbf{S i O}} \mathbf{3} \\
\left(\mathbf{k g} / \mathbf{m}^{\mathbf{3}}\right)\end{array}$ & $\begin{array}{c}\text { Fine Aggregate } \\
\left(\mathbf{k g} / \mathbf{m}^{\mathbf{3}}\right)\end{array}$ & $\begin{array}{c}\text { Coarse Aggregate } \\
\left(\mathbf{k g} / \mathbf{m}^{\mathbf{3}}\right)\end{array}$ \\
\hline $0 \%$ & 408 & 50 & 125 & 592 & 1257 \\
$5 \%$ & 388 & 50 & 125 & 592 & 1257 \\
$10 \%$ & 367 & 50 & 125 & 592 & 1257 \\
$15 \%$ & 347 & 50 & 125 & 592 & 1257 \\
\hline
\end{tabular}

\subsection{Structural characterization techniques}

X-ray diffraction characterization was performed (Model: ULTIMA-III, make: Rigaku Corporation Japan) using $\mathrm{CuK} \alpha$ as a radiation source with a step size of $0.02^{\circ}$ and the scan range of $30^{\circ}$ to $80^{\circ}$. From the recorded XRD pattern, the structural behaviors such as the crystallite size effect and phase transformation effect were understood. The microstructures of UFGGBFS and fly ash were taken using a scanning electron microscope (SEM) (Model: EVO 18 ZEISS, USA), the apparent particle size and morphology were studied.

\section{RESULTS AND DISCUSSION}

\subsection{Effect of compressive strength}

GPC cube of size $150 \mathrm{~mm}$ x $150 \mathrm{~mm} \times 150 \mathrm{~mm}$ was cast and tested as per [27]. All the specimens were ambient cured for 56 days. Figure 3 shows the average value obtained for UFGGBFS based GPC. It can be observed from Figure 3 that with rising molarity and UFGGBFS the compressive strength of all mixes after 56 days ambient curing was found to be improving. The average compressive strength of UFGGBFS $0 \%$ for $10 \mathrm{M}, 12 \mathrm{M}$ and $14 \mathrm{M}$ were found to be $39.31 \mathrm{MPa}, 47.59$ $\mathrm{MPa}$ and $50.66 \mathrm{MPa}$ respectively. An increase in the percentage of UFGGBFS improved the strength performance for all the molar ratios. When comparing $15 \%$ replacement of UFGGBFS with fly ash between $10 \mathrm{M}$ and 12M GPC the increased strength percentage was found to be $14.84 \%$, similarly, when comparing $10 \mathrm{M}$ and $14 \mathrm{M}$ GPC for $15 \%$ UFGGBFS and $85 \%$ fly ash, increase of the strength percentage was found to be $18.05 \% .347 \mathrm{~kg} / \mathrm{m}^{3}$ of fly ash and $61 \mathrm{~kg} / \mathrm{m}^{3}$ of UFGGBFS showed good strength value when compared to other combinations for all the molarity. Incorporation of UFGGBFS with fly ash improves the densification process. Improvement of strength occurs mainly due to the effect of calcium in UFGGBFS and fly ash [11]. The dissolution of silicates occurs mainly due to the amorphous nature of CPS which enriches alkaline activation and results in improvement of its strength [28]. A lot of early age results were examined in previous studies [16, 29], 56 days ambient cured compressive strength results were examined to check its strength performance. 


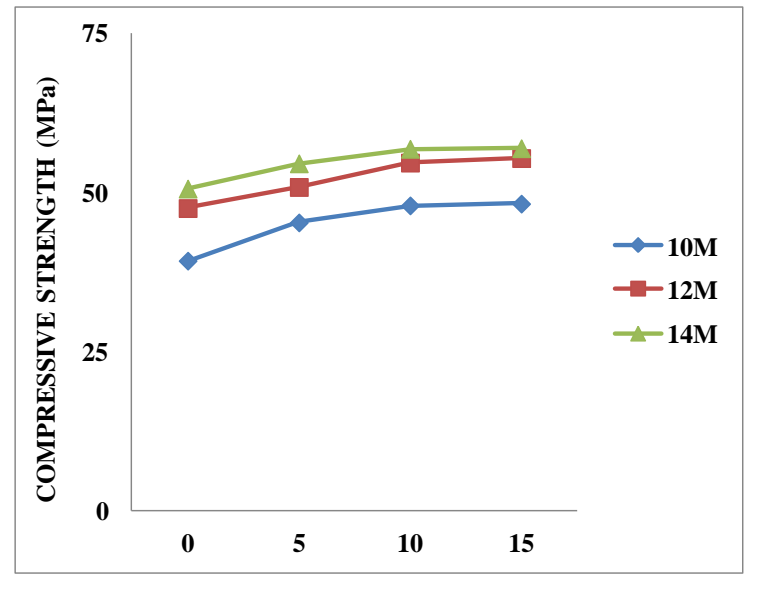

Figure 3. Compressive strength of UFGGBFS, Fly ash and CPS based GPC

\subsection{Evaluation of voids in GPC}

As per ASTM C642 [30], the volume of pores was evaluated. Disk specimen of $100 \mathrm{~mm}$ diameter and $50 \mathrm{~mm}$ height was subjected to experimental work after 180 days ambient curing [30] for 10M,12M and 14M GPC. Figure 4 shows the percentage of voids. It can be seen from Figure 4 that GPC made of UFGGBFS, fly ash and CPS plays an essential role in reducing the porosity. When comparing the results of $10 \mathrm{M}$, $12 \mathrm{M}$ and $14 \mathrm{M}$ GPC volume of voids for UFGGBFS $0 \%$ was found to be $9.09 \%, 9.01 \%$ and $8.92 \%$ respectively. Percentage of volume of voids for UFGGBFS $15 \%$ was found to be $6.62 \%, 6.47 \%$ and $6.1 \%$ respectively, up to $8.5 \%$ reduction of voids is achieved when comparing $10 \mathrm{M}$ and 14M GPC. While comparing 10M, 12M and 14M GPC for all GPC combination it indicates that the increase of molarity and UFGGBFS percentage reduces the voids percentage. Lower porosity results in refined structure along with steady stress distribution which attributes to elevated compressive strength [31, 32]. Alkali activation of UFGGBFS results in formation of CASH gel and thus reducing porosity.

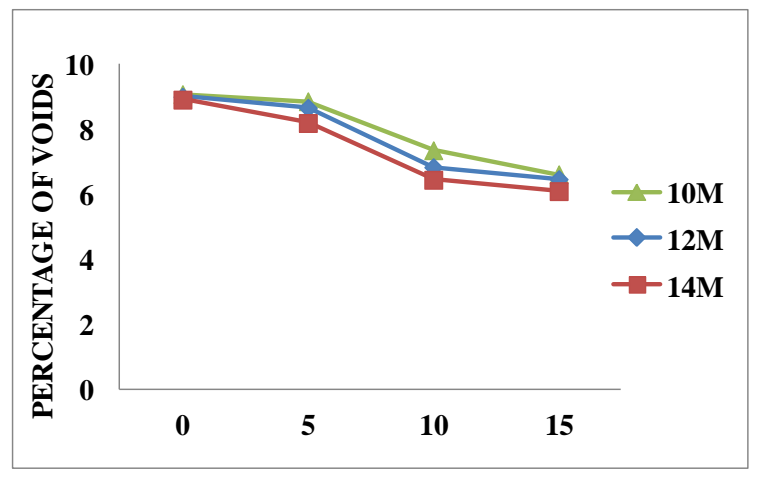

Figure 4. Effect of UFGGBFS based GPC against voids

\subsection{Rapid Chloride Permeability Testing (RCPT)}

According to ASTMC1202 standards [33], Rapid Chloride Permeability Test (RCPT) was conducted on the GPC specimen after 180 days of ambient curing. Figure 5 shows the RCPT results. Figure 6 shows the RCPT Test setup. From Figure 5 it is observed that charges passed were found to be lesser. $10 \mathrm{M}$ of GPC shows slightly higher chloride permeability when compared to $12 \mathrm{M}$ and $14 \mathrm{M}$, but also, it comes under the low category. As far as $12 \mathrm{M}$ of GPC is considered UFGGBFS $10 \%$ and $15 \%$ comes under very low category. In the case of 14M GPC chloride permeability was found to very low for the entire specimen. The addition of calcium-based materials enhances the performance of GPC. These results indicate that addition of mineral admixture reduces the chloride ion penetration thereby improving the densification of GPC. GPC placed in very low range indicates the possibility of chloride ion permeability, age of curing decreases the total charge passed indicating good microstructure modification. An increase in calcium reduces the pores [34].

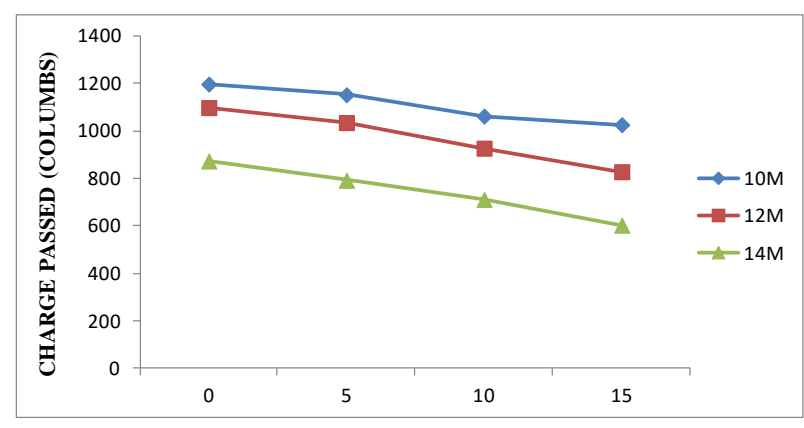

Figure 5. RCPT results of UFGGBFS, Fly ash and CPS based GPC

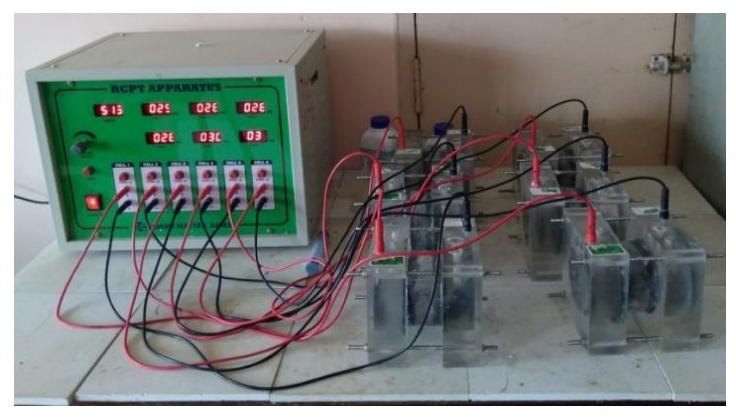

Figure 6. RCPT test setup

\subsection{Structural behavior of UFGGBFS and fly ash materials}

Figure 7a-b shows the XRD profiles of fly ash and UFGGBFS respectively. Figure $7 \mathrm{a}$ exhibits the presence of nine distinct types of phases of composite material in the crystalline nature, which is pointed out by the sharp peaks. They are represented as $\mathrm{SiO}_{2}, \mathrm{CaSiO}_{3}$, Mullite, $\mathrm{FeSO}_{3}, \mathrm{CaSO}_{4}$, $\mathrm{Al}_{2} \mathrm{Ca}_{2} \mathrm{SiO}_{7}, \mathrm{CaS}, \mathrm{MgO}$ and $\mathrm{FeSi}$. In various types of phases, $\mathrm{SiO}_{2}$ is confirmed as a major dominant phase of composite material and the other types of phases are considered as secondary formation of phases. The well-defined diffraction peaks appeared at angles of $20.91^{\circ}, 25.50^{\circ}, 26.70^{\circ}, 29.38^{\circ}$, $31.39^{\circ}, 33.19^{\circ}, 36.624^{\circ}, 39.51^{\circ}, 40.357^{\circ}, 40.96^{\circ}, 42.480^{\circ}$, $50.187^{\circ}, 52.12^{\circ}, 60.005^{\circ}, 67.917^{\circ}, 68.387^{\circ}, 73.431^{\circ}$ and $75.778^{\circ}$. The major dominant phase, $\mathrm{SiO}_{2}$ exhibited a hexagonal crystal structure with a space group of P3121. It is well matched with the ICDD reference code of 98-006-5144 and appeared at $20.91^{\circ}, 26.70^{\circ}, 36.624^{\circ}, 39.51^{\circ}, 40357^{\circ}$, $42.557^{\circ}, 50.187^{\circ}, 54.987^{\circ}, 60.005^{\circ}, 67.917^{\circ}, 68.387^{\circ}, 73.431^{\circ}$ and $75.778^{\circ}$ angles corresponding to $(010),(011),(110),(012)$, (111), (020), (112), (022), (121), (122), (023), (014) and (032) planes respectively. The other peaks are considered as secondary formation of phases such as $\mathrm{CaSiO}_{3}, \mathrm{Mullite}, \mathrm{FeSO}_{3}$, $\mathrm{CaSO}_{4}, \mathrm{Al}_{2} \mathrm{Ca}_{2} \mathrm{SiO}_{7}, \mathrm{CaS}, \mathrm{MgO}$ and FeSi. The secondary 
formation of phases in fly ash sample is represented in Figure 7a. The calculated average crystallite size of this $\mathrm{SiO}_{2}$ based composite powder is $288 \mathrm{~nm}$.

Figure $7 \mathrm{~b}$ exhibits the presence of amorphous phase of material, which is non-crystalline in nature and it is indicated by the rambling type of peak without sharpness and it is confirmed as quartz material.

The SEM images of fly ash and UFGGBFS and their distribution plots of the particle sizes are shown in Figure 8a$\mathrm{d}$ respectively. The calculated average particle size of fly ash and UFGGBFS powder is $1.07 \mu \mathrm{m}$ and $3.9 \mu \mathrm{m}$ respectively. The polydispersity percentage of fly ash and UFGGBFS powder is $10.28 \%$ and $34.36 \%$ respectively. The mechanical performances of the materials are prominently enhanced by the agglomerated and refined powder particles. The SEM images show that the apparent morphology of $\mathrm{SiO}_{2}$ based fly ash particles. They have the angular unequiaxed surface with a poorly rounded cross-sectional type of morphology. The XRD profiles have shown that the calculated average crystallite sizes of fly ash are in good bonding with the calculated mean particle sizes of the respective composite particles, which are obtained from the SEM microstructures. The SEM images show that the UFGGBFS particles have the combination of angular unequiaxed and equiaxed surfaces with poorly rounded cross-sectional morphology. From the SEM analyses it is inferred that particle size and micro pores of the fly ash and UFGGBFS improves the strength and performance of GPC. Due to its particle size and its fineness when incorporated in GPC it improves its microstructure and makes the concrete impermeable.

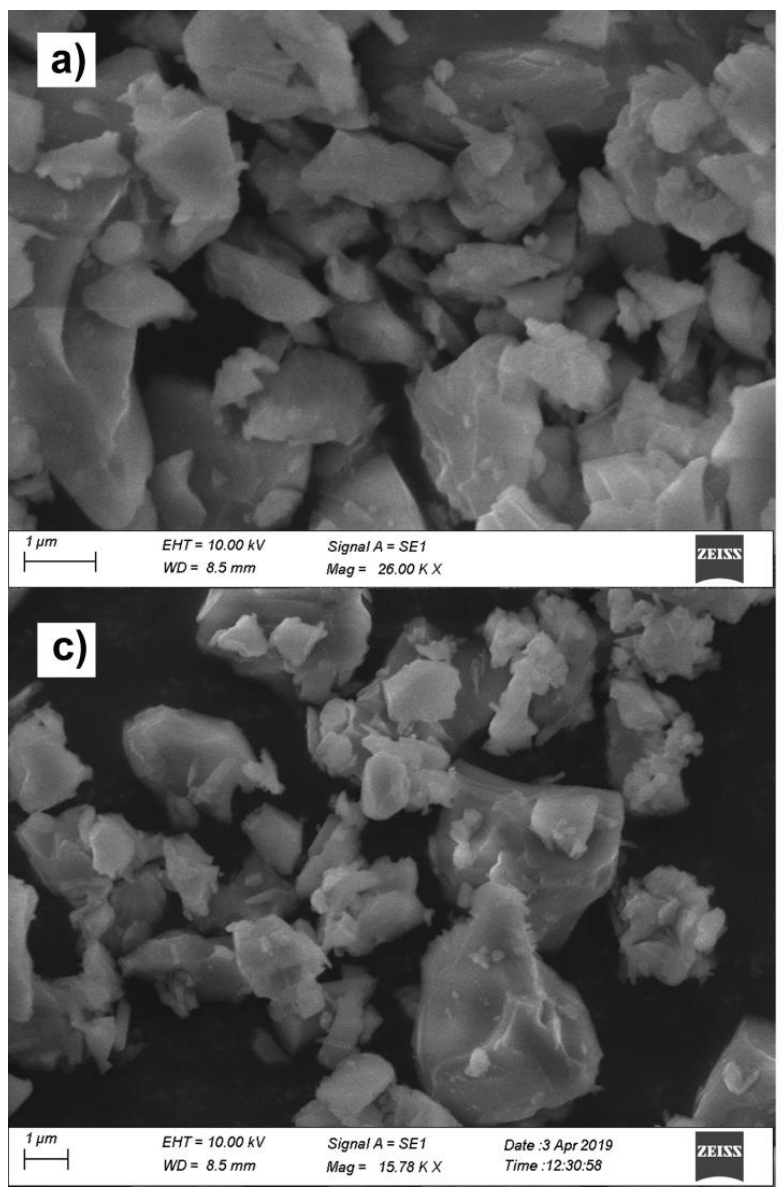

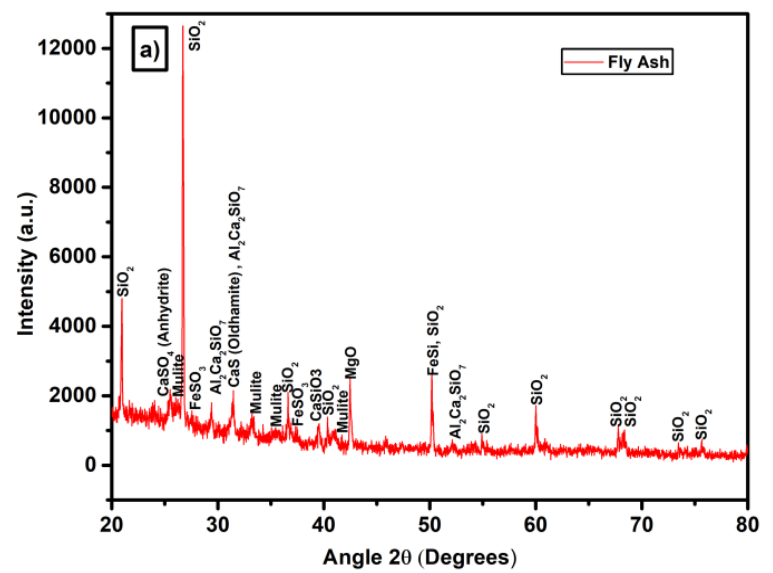

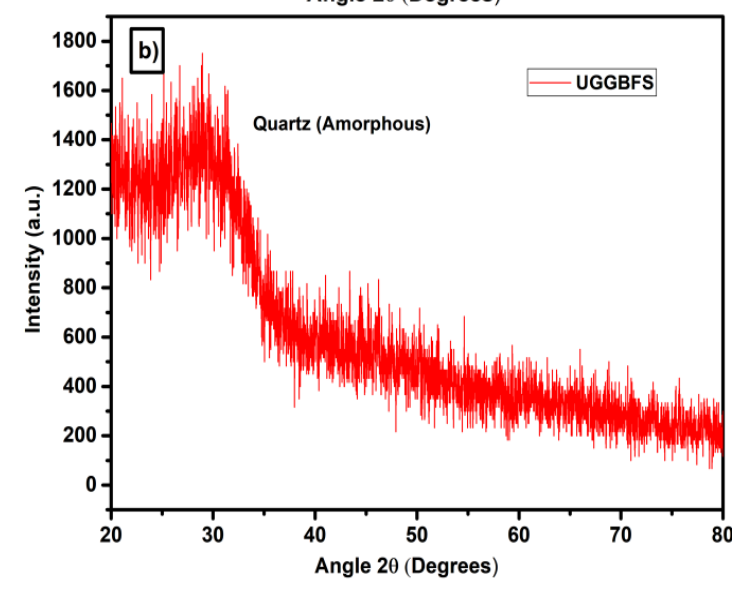

Figure 7. XRD profiles: a) fly ash and b) UFGGBFS
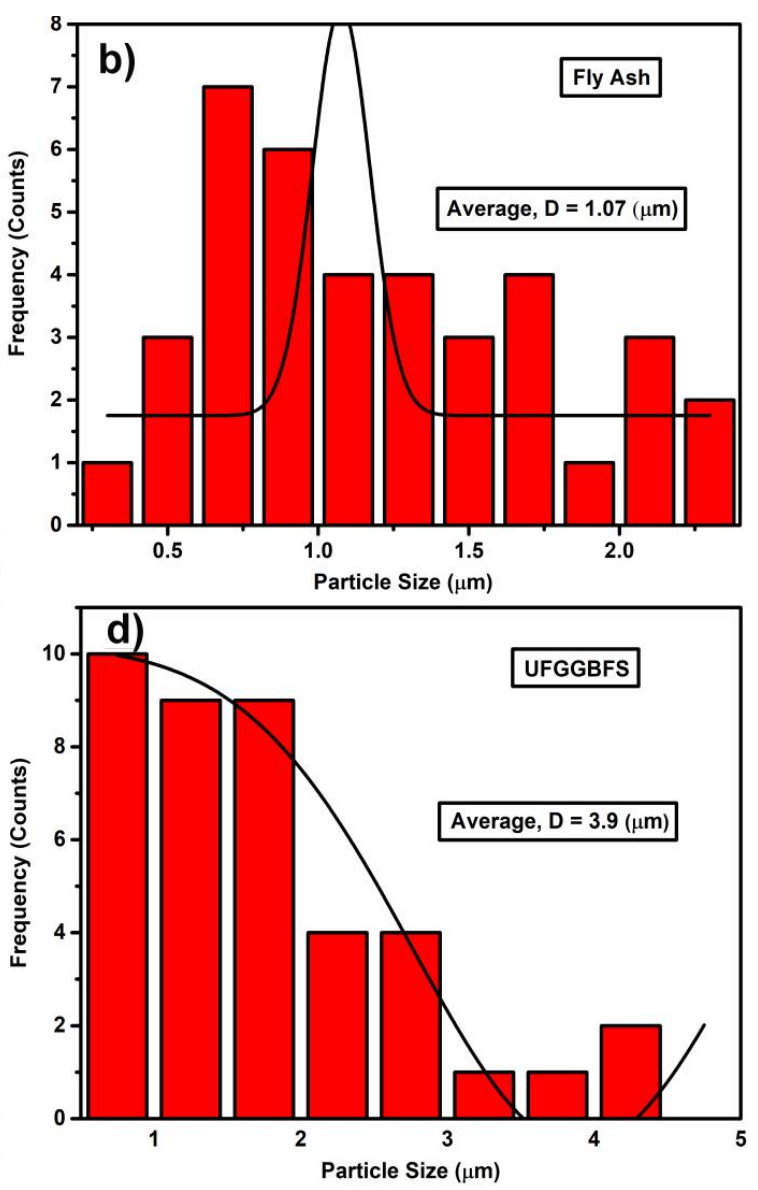

Figure 8. SEM images: a) Morphology of fly ash b) Particle size distribution of fly ash c) Morphology of UFGGBFS and d) Particle size distribution of UFGGBFS 


\section{CONCLUSIONS}

Based on this study the following conclusions were drawn:

1) GPC compressive strength for $10 \mathrm{M}, 12 \mathrm{M}$ and $14 \mathrm{M}$ increases with the addition of UFGGBFS as replacement of low calcium fly ash up to $15 \%$.

2) Compressive strength of all mix combination with UFGGBFS, fly ash and CPS at 56 days ambient curing was found to be better. For 10M GPC with $15 \%$ UFGGBFS the strength achieved is $48.29 \mathrm{MPa}$. Similarly for $12 \mathrm{M}$ and $14 \mathrm{M}$ it is $55.46 \mathrm{MPa}$ and $57.01 \mathrm{MPa}$ respectively.

3) From compressive strength test results it is concluded that the addition of UFGGBFS and CPS helps to achieve higher strength from $39 \mathrm{MPa}$ to $57 \mathrm{MPa}$ for different molarities.

4) UFGGBFS (5\%,10\% and $15 \%$ ) replaced with GPC for $10 \mathrm{M}, 12 \mathrm{M}$ and $14 \mathrm{M}$ showed reduced porosity and therefore made GPC impermeable.

5) Chloride permeability was found to be in very low range for 14M GPC. Addition of UFGGBFS and CPS in 10M $12 \mathrm{M}$ and $14 \mathrm{M}$ GPC showed improved chloride impermeability.

6) RCPT proved that making GPC with UFGGBFS, fly ash and CPS reduces the movement of chloride ions.

7) XRD and SEM analysis proved that addition of mineral admixtures improved the bonding of GPC.

8) Using UFGGBFS, fly ash along with CPS improves the ambient curing and therefore can be used in practical application.

9) Using UFGGBFS, fly ash and CPS is eco-friendly and can be used as an alternative material in the manufacturing of cementitious GPC.

\section{ACKNOWLEDGMENT}

The Authors are thankful to the Director, National Institute of Technology, Trichy, TamilNadu, India for providing the facilities to carry out the research work.

\section{REFRENCES}

[1] Malhotra, V.M. (1999). Making concrete greener with fly ash. ACI Concrete International, 21(5): 61-66. https://doi.org/10.1016/S0958-9465(99)00006-2

[2] Malhotra, V.M. (2002). Introduction: sustainable development and concrete technology. Concrete International, 24(7): 1-22.

[3] Puertas, F. (1995). Cementos de escoria activados alcalinamente: situación actual perspectivas de future. Mater Constr, 45(239): 53-64. http://dx.doi.org/10.3989/mc.1995.v45.i239.553

[4] Wang, S.D., Pu, X.C., Scrivener, K.L., Pratt, P.L. (1995). Alkali-activated slag cement and concrete: A review of properties and problems. Adv. Cem. Res, 7(27): 93-102. http://dx.doi:10.1680/adcr.1995.7.27.93

[5] Pacheco-Torgal, F., Labrincha, J.A., Leonelli, C., Palomo, A., Chindaprasirt, P. (2015). Handbook of Alkali-activated Cements, Mortars and Concretes. Woodhead Publishing, Elsevier, 1-16. https://doi.org/10.1533/9781782422884.1

[6] McLellan, B.C., Williams, R.P., Lay, J., Van Riessen, A.,
Corder, G.D. (2011). Costs and carbon emissions for geopolymer pastes in comparison to ordinary Portland cement. J. Cleaner Prod, 19(9): 1080-1090. https://doi.org/10.1016/j.jclepro.2011.02.010

[7] Junaid, M.T., Khennane, A., Kayali, O., Sadaoui, A., Picard, D., Fafard, M. (2014). Aspects of the deformational behaviour of alkali activated fly ash concrete at elevated temperatures. Cem. Concr. Res, 60: 24-29. https://doi.org/10.1016/j.cemconres.2014.01.026

[8] Ahmed, M.F., Nuruddin, M.F., Shafiq, N. (2011). Compressive strength and workability characteristics of low-calcium fly ash-based self-compacting Geopolymer concrete. Int. J. Civil Environ. Eng, 3(2): 72-78.

[9] Junaid, M.T., Khennane, A., Kayali, O. (2015). Performance of fly ash based Geopolymer concrete made using non-pelletized fly ash aggregates after exposure to high temperatures. Mater. Struct, 48(10): 3357-3365. https://doi.org/10.1617/s11527-014-0404-6

[10] Mehta, A., Siddique, R. (2016). An overview of geopolymers derived from industrial byproducts. Constr. Build. $\quad$ Mater, 127: 183-198. https://doi.org/10.1016/j.conbuildmat.2016.09.136

[11] Parveen., Singhal, D., Junaid, T.M., Jindal, B.B., Mehta, A. (2018). Mechanical and microstructural properties of fly ash based geopolymer concrete incorporating alccofine at ambient curing. Constr Build Mater, 180: 298-307. https://doi.org/10.1016/j.conbuildmat.2018.05.286

[12] Palomo, A., Fernandez-Jimenez, A., Kovalchuk, G., Ordonez, L.M., Naranjo, M.C. (2007). Opc fly ash cementitious systems: study of gel binders produced during alkaline hydration. J. Mater. Sci, 42: 2958-2966. https://doi.org/10.1007/s10853-006-0585-7

[13] Hu, S.G., Wang, H.X., Zhang, G.Z., Ding, Q.J. (2008). Bonding and abrasion resistance of geopolymeric repair material made with steel slag. Cem. Concr. Compos, 30(3):

239-244. https://doi.org/10.1016/j.cemconcomp.2007.04.004

[14] Chindaprasirt, P., Chareerat, T., Hatanaka, S., Cao, T. (2011). High-strength Geopolymer using fine highcalcium fly ash. J. Mater. Civ. Eng, 264-270. https://doi.org/10.1061/(ASCE)MT.1943-5533.0000161

[15] Gorai, B., Jana, R.K., Premchand, M. (2003). Characteristics and utilization of copper slag-a review. Resour. Conser. Recycl, 39(4): 299-313. https://doi.org/10.1016/S0921-3449(02)00171-4

[16] Mahendran, K., Arunachelam, N. (2016). Performance of fly ash and copper slag based geopolymer concrete. Indian Journal of Science and Technology, 9(2): 09745645. https://doi.org/10.17485/ijst/2016/v9i2/86359

[17] Marghussian, V.K., Maghsoodipoor, A. (1999). Fabrication of unglazed floor tiles containing Iranian copper slags. Ceram. Int, 25(7): 617-622. https://doi.org/10.1016/S0272-8842(98)00075-3

[18] Al-Jabri, K.S., Al-Saidy, A.H., Taha, R., (2011). Effect of copper slag as a fine aggregate on the properties of cement mortars and concrete. Const. Build. Mater, 25(2): 933-938. https://doi.org/10.1016/j.conbuildmat.2010.06.090

[19] Arino, A.M., Mobasher, B. (1999). Effect of ground copper slag on strength and toughness of cementitious mixes. ACI Materials Journal, 96(1): 68-73.

[20] Yang, Z.H., Lin, Q., Lu, S.C., He, Y., Liao, G.D., Ke, Y. (2014). Effect of $\mathrm{CaO} / \mathrm{SiO}_{2}$ ratio on the preparation and 
crystallization of glass-ceramics from copper slag. Ceram. Int, 40(5): 7297-7305. https://doi.org/10.1016/j.ceramint.2013.12.071

[21] IS-383 (1970). Specification for Coarse and Fine Aggregates from Natural Sources for Concrete. 2nd Revision, Bureau of Indians Standards, New Delhi.

[22] ASTM C989-99 (1999). Standard Specification for Ground Granulated Blast-Furnace Slag for Use in Concrete and Mortars. ASTM International, West Conshohocken, PA. https://doi.org/10.1520/C0989-99

[23] IS 9103-1999 Indian Standard Concrete Admixtures Specification, Bureau of Indian Standards, New Delhi, India.

[24] Pavithra, P., Reddy, M.S., Dinakar, P., Rao, B.H., Satpathy, B., Mohanty, A. (2016). A mix design procedure for geopolymer concrete with fly ash. J. Cleaner Prod., 133: 117-125. https://doi.org/10.1016/j.jclepro.2016.05.041

[25] Jangra, P., Singhal, D. (2017). Development of mix design method for Geopolymer concrete. Adv. Constr., 5(4): 377-390. https://doi.org/10.12989/acc.2017.5.4.377

[26] Junaid, M.T., Kayali, O., Khennane, A., Black, J. (2015). A mix design procedure for low calcium alkali activated fly ash-based concretes. Constr. Build. Mater, 79: 301310. https://doi.org/10.1016/j.conbuildmat.2015.01.048

[27] IS 516-1959 Indian Standard Methods of Tests for Strength of Concrete, Bureau of Indian Standards, New Delhi, India.

[28] Nazer, A., Pay, J., Monzo, J. (2016). Use of ancient copper slags in Portland cement and alkali activated cement matrices. J. Environ. Manage, 167: 115-123. https://doi.org/10.1016/j.jenvman.2015.11.024

[29] Singh, J., Singh, S.P. (2019). Development of Alkali- activated cementitious material using copper slag. Constr. Build. Mater., 211: 73-79. https://doi.org/10.1016/j.conbuildmat.2019.03.233

[30] American Society for Testing and Materials (ASTM). (2013). Standard test method for density, absorption, and voids in hardened concrete, ASTM C642, ASTM International, West Conshohocken, PA.

[31] Ma, Y., He, J., Ye, G. (2013). The pore structure and permeability of alkali activated fly ash. Fuel, 104: 771780. https://doi.org/10.1016/j.fuel.2012.05.034

[32] Toniolo, N., Boccaccini, A.R. (2017). Fly ash-based geopolymers containing added silicate waste, A review. Ceram. Int, 43(17): 14545-14551. https://doi.org/10.1016/j.ceramint.2017.07.221

[33] ASTM C1202. (2012). Standard Test Method for Electrical Indication of Concrete's Ability to Resist Chloride Ion Penetration, ASTM, West Conshohcken, PA.

[34] Skvara, F., Kopecky, L., Nimeeek, J., Bittnar, Z. (2006). Microstructure of Geopolymer materials based on fly ash. Ceram. Silik, 4: 208-215.

\section{NOMENCLATURE}

$\begin{array}{ll}\text { MPa } & \text { Mega pascal } \\ \text { GPC } & \text { Geopolymer Concrete } \\ \text { CPS } & \text { Copper Slag } \\ \text { B } & \text { Full width at half maximum of peak } \\ & \text { intensity } \\ \text { d } & \text { Crystallite size } \\ \text { XRD } & \text { X-ray Powder Diffraction } \\ \text { SEM } & \text { Scanning Electron Microscope }\end{array}$

